This manuscript has been submitted for publication in JOURNAL OF GEOPHYSICAL RESEARCH: PLANETS. Please note that, despite having undergone peer-review, the manuscript has yet to be formally accepted for publication. Subsequent versions of this manuscript may have slightly different content. If accepted, the final version of this manuscript will be available via the 'Peer-reviewed Publication DOI' link on the right-hand side of this webpage. Please feel free to contact any of the authors; we welcome feedback. 


\section{The large-scale troughs on Asteroid 4 Vesta accommodate opening-mode}

\section{3 displacement}

$4 \quad$ Hiu Ching Jupiter Cheng ${ }^{1}$ and Christian Klimczak ${ }^{1}$

$5{ }^{1}$ Structural Geology and Geomechanics Group, Department of Geology, University of Georgia,

6 Athens, GA 30602, USA

7 Key Points:

- Our observations are inconsistent with the previously proposed fault origin of the troughs and point to an opening-mode fracture origin.

- Rock mechanical calculations reveal that jointing is the favorable fracturing mode in at least the upper $\sim 14 \mathrm{~km}$ of Vesta's lithosphere.

- The topographic expressions of large-scale troughs on Vesta are caused by opening-mode displacements from jointing.

\section{Abstract}

The Dawn mission at Asteroid 4 Vesta revealed two sets of enormous troughs, with the Divalia Fossae spanning around two-thirds of the equator and the Saturnalia Fossae located in the northern hemisphere. Based on their size and shape, these troughs were interpreted as grabens formed by faulting. An opening-mode fracture origin, however, was heretofore not considered. To distinguish between those origins, we investigate the map patterns, cross-sectional geometries, and variations of relief and width along the trough lengths. Relief and width are meaningful measurements that directly relate to the vertical displacement of faults and aperture of joints, respectively; thus, they may reveal differences in fracturing behavior. We map all major troughs 
23 on Vesta, including four as Divalia Fossae and two as Saturnalia Fossae. No map patterns

24 diagnostic for faulting and jointing were identified. The troughs are bounded by scalloped rims

25 and mainly show bowl-shaped cross-sectional geometries. The variations of the relief of each pair

26 of trough-bounding scarps show maxima off-center and at different locations along the trough they

27 bound. In contrast, variations in trough width have their maxima near the trough centers. These

28 characteristics are inconsistent with the mechanics of graben formation but are consistent with

29 jointing and thus point to an opening-mode fracture origin. Our rock-mechanical calculations

30 reveal that jointing is the favorable fracturing mode in at least the upper $\sim 14 \mathrm{~km}$ of Vesta's

31 lithosphere, consistent with it being a low-gravity body. Therefore, the troughs must have

32 accommodated opening-mode displacements from jointing, which has implications for other low33 gravity bodies.

Plain Language Summary

The camera on the Dawn spacecraft captured two sets of large linear depressions, or troughs, on asteroid Vesta. Previous studies suggested that these troughs are fault-bounded valleys

37 with a distinct scarp on each side that together mark the down-drop (sliding) of a block of rock.

38 However, rock can also crack apart and form such troughs, an origin that has not been considered

39 before. Structures formed by sliding and cracking form different map patterns, have different 40 morphologic expressions and are controlled by different stresses acting on the rock volume.

41 Although our observations do not display any diagnostic map patterns, the morphology of the

42 troughs is consistent with cracking, whereby the trough is the widest at the middle and narrows

43 towards the two ends. Our calculations also show that stresses are not favorable for sliding to occur

44 within the uppermost $\sim 14 \mathrm{~km}$ of Vesta's rock volume, but instead, the physics shows that rocks

45 there are favored to crack apart. Therefore, the formation of these troughs must involve the opening 
46 of cracks, which is also important for understanding landforms on small planetary bodies

47 elsewhere in the Solar System.

48 Keywords: planetary tectonics, Vesta, normal faulting, opening-mode fracture

49

50

51

52

53

54

55

56

57

58

59

60

61

62

63

64

65

66

67

\section{Introduction}

\subsection{Vesta's tectonics}

The Dawn mission (Russell and Raymond, 2011) explored Asteroid 4 Vesta and revealed the presence of two sets of large-scale linear structures (Figure 1). The Divalia Fossae vary in width from several hundreds of meters up to about $20.5 \mathrm{~km}$, bounded by steep scarps, and encircling about two-thirds of the asteroid. The Saturnalia Fossae are oriented northwest-southeast and show a difference in orientation from the Divalia Fossae of approximately $30^{\circ}$. They are exposed only in the northern hemisphere with their southern extent truncated by the Divalia Fossae. The photomosaics and digital terrain model derived from Dawn Framing Camera (FC) images (Sierks et al., 2011) allow for detailed mapping and structural analysis of these troughs. Poles of vertical planes defined along the Divalia and Saturnalia Fossae are found to cluster near the center of the Rheasilvia and Veneneia impact basins at the south pole, respectively, which was interpreted as evidence for an impact-induced origin of these troughs (Jaumann et al., 2012; Figure 1).

The Divalia Fossae are observed to be flat-floored and interpreted as grabens, formed by normal faulting, with vertical displacements in excess of $5 \mathrm{~km}$ (Buczkowski et al. 2012). Subsequently, multiple studies have interpreted Divalia Fossa and similar troughs on Vesta as grabens, half-grabens, and horst-graben structures (Ruesch et al., 2014; Schäfer et al., 2014; Scully et al., 2014; Yingst et al., 2014). Several modeling studies have considered the specific tectonic causes for the faulting, including numerical modeling to simulate the amount of deformation 
associated with the formation of the Rheasilvia basin (Bowling et al., 2013), and combining

69 laboratory and numerical experiments to model subsurface failure as a consequence of oblique

70 impacts into a spherical target (Stickle et al., 2015). However, the rheology and brittle strength of

71 Vesta's lithosphere have not been evaluated, and other fracture types have not been considered to

72 explain in the tectonics of the asteroid. In particular, opening-mode fracturing, such as jointing, is

73 a ubiquitous fracturing behavior in the upper portion of the Earth's lithosphere, and it is unknown

74 how important they are in the formation of the troughs.

75

76

77

78

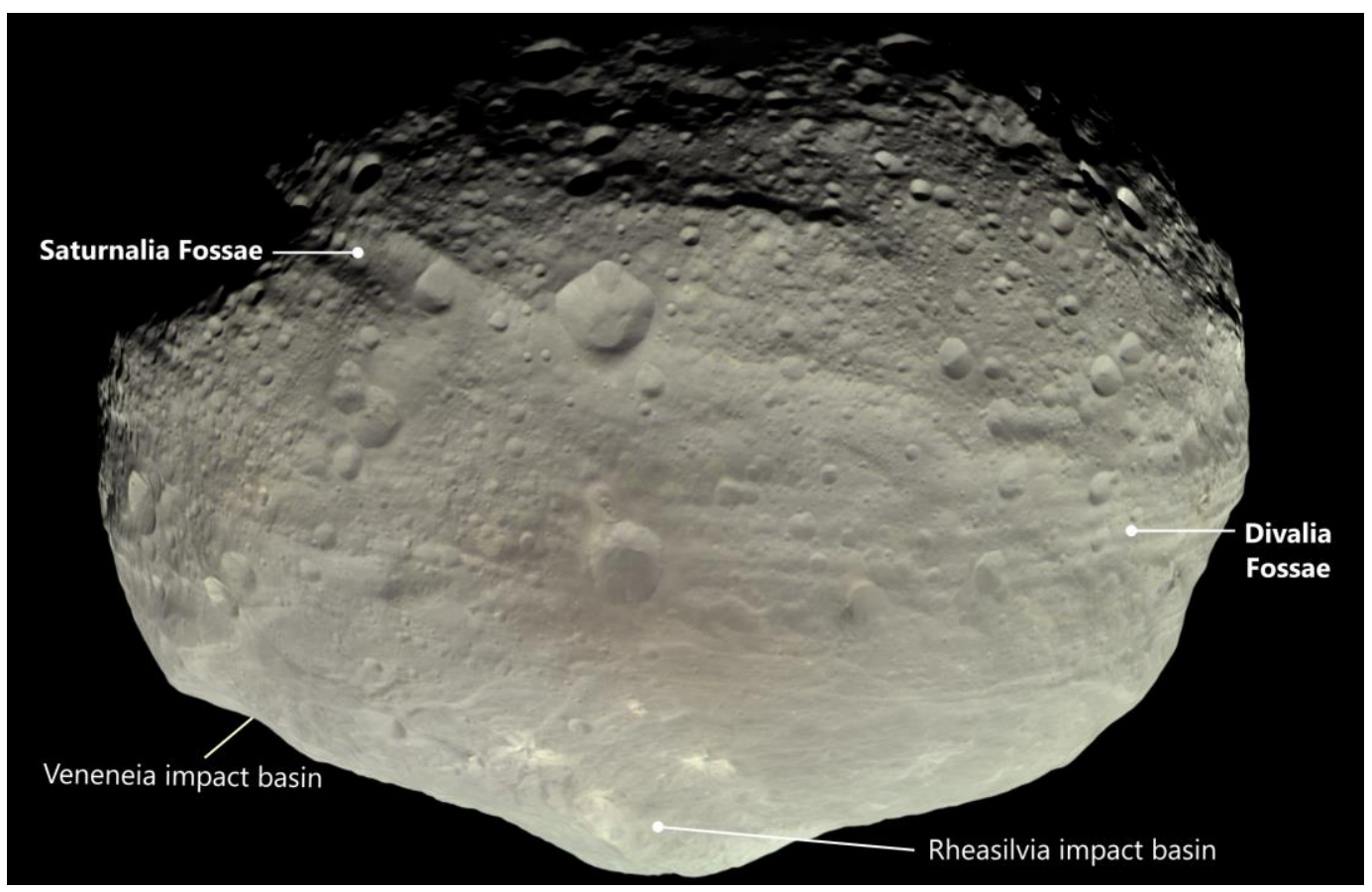

Figure 1. Image of Asteroid 4 Vesta, showing the locations of the Divalia and Saturnalia Fossae, and the Veneneia and Rheasilvia impact basins. The image was captured by the NASA Dawn mission on 24 July 2011 with image processing by Björn Jónsson. <1.5-column figure> 


\subsection{Normal faulting vs. Jointing}

Brittle failure in an extensional tectonic regime, where the overburden pressure represents

82 the maximum principal stress, occurs through the formation of joints or slip on normal faults.

83 Joints are planar discontinuities in rock, where the fracture walls move perpendicularly apart from

84 one another forming opening displacement (Pollard and Aydin, 1988), and thus they are considered opening-mode fractures along with veins and dikes. In contrast, faulting shows movement parallel to the fault plane, which is referred to as sliding-mode or tearing-mode fracturing.

Joints form when tensile stresses reach the tensile strength of the rock in a direction largely perpendicular to the fracture plane. Normal fault displacement is achieved by frictional sliding when the hanging wall, the rock mass above the fault plane, slips down relative to the footwall, the rock mass beneath the fault plane. Frictional sliding occurs only when all principal stress 91 components are compressive, the maximum stress is oriented vertically and equal to the overburden pressure, and the minimum principal stress acts horizontally.

In a lithosphere under extension, joints propagating from the surface to depth reach a critical depth, where they reactivate as normal faults when the overburden is large enough to shift tensile stresses into the compressive regime. Such fractures possess opening-mode and slidingmode displacements, i.e., they are hybrid or mixed-mode fractures. Mixed-mode fractures are

97 commonly observed associated with large rift zones on Earth, such as the Almannagjá normal fault at the Reykjaneshryggur-Langjökull rift system of southwest Iceland (Gudmundsson, 1992, 2011), Koa'e fault system associated with the Kīlauea volcano rift zone in Hawaii (Holland et al, 2006), and the Wonji Fault Belt associated with the Ethiopian Rift in East Africa (Acocella et al., 2003). For Earth's gravitational acceleration and a basaltic crust, the jointing-faulting transition occurs at 
800 meters depth (Gudmundsson, 2011). With lower gravitational accelerations, this transition should occur much deeper in the lithospheres of small bodies, such as moons and asteroids. Hence, opening-mode displacement should be an important attribute of structures formed in extensional tectonic regimes on small bodies. However, opening-mode or mixed-mode fractures have not attracted much attention in the planetary community. Establishing the fracturing mode when interpreting brittle structures on planetary bodies is important because it dictates our interpretations of the stress regime, as well as kinematics and mechanics of the tectonics responsible for forming the structures.

Structures formed by jointing and normal faulting can be distinguished from one another by their map patterns, cross-sectional geometries, and displacement distribution, which all have been widely studied in numerous fracturing systems on Earth and other planetary bodies. Normal faults commonly appear as grabens, which are narrow, negative relief structures bounded by oppositely dipping normal faults, with dip directions toward one another, that create a downdropped block in the center (Melosh and Williams Jr, 1989; Schultz et al., 2007; Fossen, 2016). Grabens display a wide range of map patterns, some of which are diagnostic for normal faulting and are found on many different planetary bodies. They generally have straight to arcuate bounding scarps and are commonly segmented, showing en échelon patterns and transfer zones between overstepping segments, also referred to as relay ramps (Peacock and Sanderson, 1994; Crider and Pollard, 1998). Grabens may also involve multiple faulted borders and floors, which is analogous to those observed in complex terrestrial rift systems (Hauber and Kronberg, 2005). In some cases, pit crater chains, which are connected circular depressions that form by the collapse of material into subsurface voids, are found aligned with or superimposed within graben, such as in those documented in detail in Hawaii (Okubo and Martel., 1998) and on Mars (Wyrick et al., 2004). In 
125 terms of displacement, their maxima are typically centrally located along the faults tapering to zero 126 at the fault tips (e.g., Dawers et al., 1993). Displacements scale positively and linearly with fault 127 length (Schultz et al., 2006). In cross-sectional view, grabens typically appear as flat-floored 128 depressions, bounded by two (or more) scarps facing one another.

In contrast, joints can appear as the straight trace of a continuous single crack or segmented 130 and discontinuous en échelon traces of subparallel small segments in map view. Although joints 131 can occur as isolated structures, they commonly occur as sets of parallel joints. Closely spaced 132 joints may interact with each other forming hook-shaped linkages (Pollard and Aydin, 1988). Joint 133 displacement, commonly referred to as aperture, is found to reach its maximum in the center of 134 the structure, tapering out symmetrically toward the tips (Vermilye and Scholz, 1995). In map 135 view, this may appear as wide troughs that narrow toward the tips. The maximum aperture scales 136 positively and sublinearly with length (Olson, 2003). In contrast to a graben, a vertical joint can 137 be expected to appear as a narrow V shape in cross-section, but it can be degraded due to slope 138 instability to appear as a wide bowl or as a V-shape by secondary infilling of collapsed materials. In this paper, we first investigate the map patterns, cross-sectional geometries, and 140 morphological variations of the large-scale troughs in detail to assess whether they are opening141 or sliding-mode fractures. Based on the previously published interior constitution and thermal 142 evolution models, we derive strength-depth profiles to characterize the rheologic structure of 143 Vesta's lithosphere and determine the predicted fracturing behavior in its brittle regime. 144 Knowledge of how these large-scale structures form has implications for the tectonics and 145 fracturing behavior for Vesta and can also be applied to other low-gravity planetary bodies (i.e., 146 moons and asteroids). 


\section{Trough map patterns}

We use Dawn FC images with a resolution of $60 \mathrm{~m} /$ pixel and the $\sim 93 \mathrm{~m} /$ pixel digital terrain model (DTM) as a basis for structural mapping. The DTM is based on the shape model of Vesta derived from FC images, and this terrain model has a vertical accuracy of about $6 \mathrm{~m}$ (Preusker et al., 2014). The two large sets of troughs and their related landforms, the bounding scarps and pit crater chains, are included in our mapping. For our structural mapping, we use ESRI's ArcGIS software to create hillshade images with different illumination conditions and draw topographic cross-sections at $\sim 5 \mathrm{~km}$ intervals across the troughs. Trough-bounding scarps are defined where a sharp surface break is observed on the topographic profiles, which were traced on the hillshade images. Structures identified as certain troughs are mapped where negative topography is bounded by two facing scarps. Long depressions with only a single bounding scarp are mapped as inferred troughs. Troughs of any category were grouped into one structure where multiple troughs were aligned and separated by only one or several impact craters. Pit craters and chains of pit craters are included in our mapping, as they are aligned with the Divalia Fossae (Buczkowski et al., 2012; Jaumann et al., 2012) and are commonly in association with grabens on other planetary bodies (Wyrick et al., 2004). They are mapped where there is a series of at least three aligned circular to elliptical, steep-sided depressions that lack diagnostic features for impact craters or volcanic pits, including elevated rims, ejecta deposits, or lava flows.

Previous work mapped 86 and 7 trough lineaments of Divalia and Saturnalia Fossae, respectively. (Jaumann et al., 2012; Yingst et al., 2014), and those analyses did not consider that some of the troughs are part of the same structures. Based on our mapping criteria, we identified 55 individual trough lineaments comprising 155 bounding scarps as well as 30 pit crater chains (Figure 2). The structural map is included as shapefiles in the supplementary materials. Of the 55 
170 troughs, 36 are classified as certain and 19 as inferred. Among those, 30 certain and 9 inferred 171 troughs form six main structures. We assigned each of them a number increasing from south to 172 north for further analysis and presentation. The Divalia Fossae consists of closely spaced E-W 173 striking troughs 1 to 4 , with lengths of $335-815 \mathrm{~km}$ and widths up to $20.5 \mathrm{~km}$. Trough 1 consists 174 of at least three segments separated far apart by long inferred trough lineaments, while troughs 2 175 to 4 consist of certain trough lineaments superposed by few impact craters. Troughs 5 and 6 are 176 part of the Saturnalia Fossae. Trough 6 is named Saturnalia Fossa. The southern extensions of the 177 Saturnalia Fossae are truncated by the Divalia Fossae, therefore their true lengths are not preserved. 178 All troughs described are mapped as being isolated, continuous, and subparallel within their own 179 sets (Figure 2).

Map patterns diagnostic for faulting, such as en échelon segmentation, relay ramps, or 181 multiple faulted borders and floors (nested graben) were not identified for any of the structures on 182 Vesta. Instead, trough-bounding scarps are consistently scalloped (Figure 3a). The rims are too 183 scalloped or too degraded to be interpreted as normal faults. In contrast, Matronalia Rupes and 184 other scarps that form the rim of the Rheasilvia impact basin, which is proposed to be coeval to 185 the Divalia Fossae, appear remarkably fresh. Map patterns diagnostic for jointing, such as hook186 shaped linkages and en échelon traces of subparallel openings, are also not readily apparent. 187 Instead, we find that degradation and slope instability may have produced the current map 188 characteristics of the troughs. 190 mapped pit crater chains are aligned with the Divalia Fossae (Figure 2 and 3). Generally, pit crater 191 chains are located on the floors of planetary grabens (Wyrick et al., 2004), but on Vesta, none of 192 them are found to occur within a trough, i.e., in between the two bounding scarps. Pit crater chains 
on Vesta vary widely in map pattern, but their full number and extent are unclear due to the superposition of impact craters. Only trough 1 shows a direct transition from the trough into a pit crater chain (Figure 3a). This trough narrows and terminates in a pit crater chain, and smaller pits align with the trough farther away from the termination of the trough. One completely preserved 197 pit crater chain has larger pits in the middle and smaller pits at the two ends of the chain (Figure 3b). Following these map observations, the structures possibly represent multiple stages of trough formation where the scalloped edges of the troughs may be coalesced pits forming from collapsed openings and unstable slopes. That pits are larger towards the center of the chain indicates the opening-mode displacement profile of a joint. Therefore, the large-scale troughs could be coalesced pits that formed from collapsed joints.

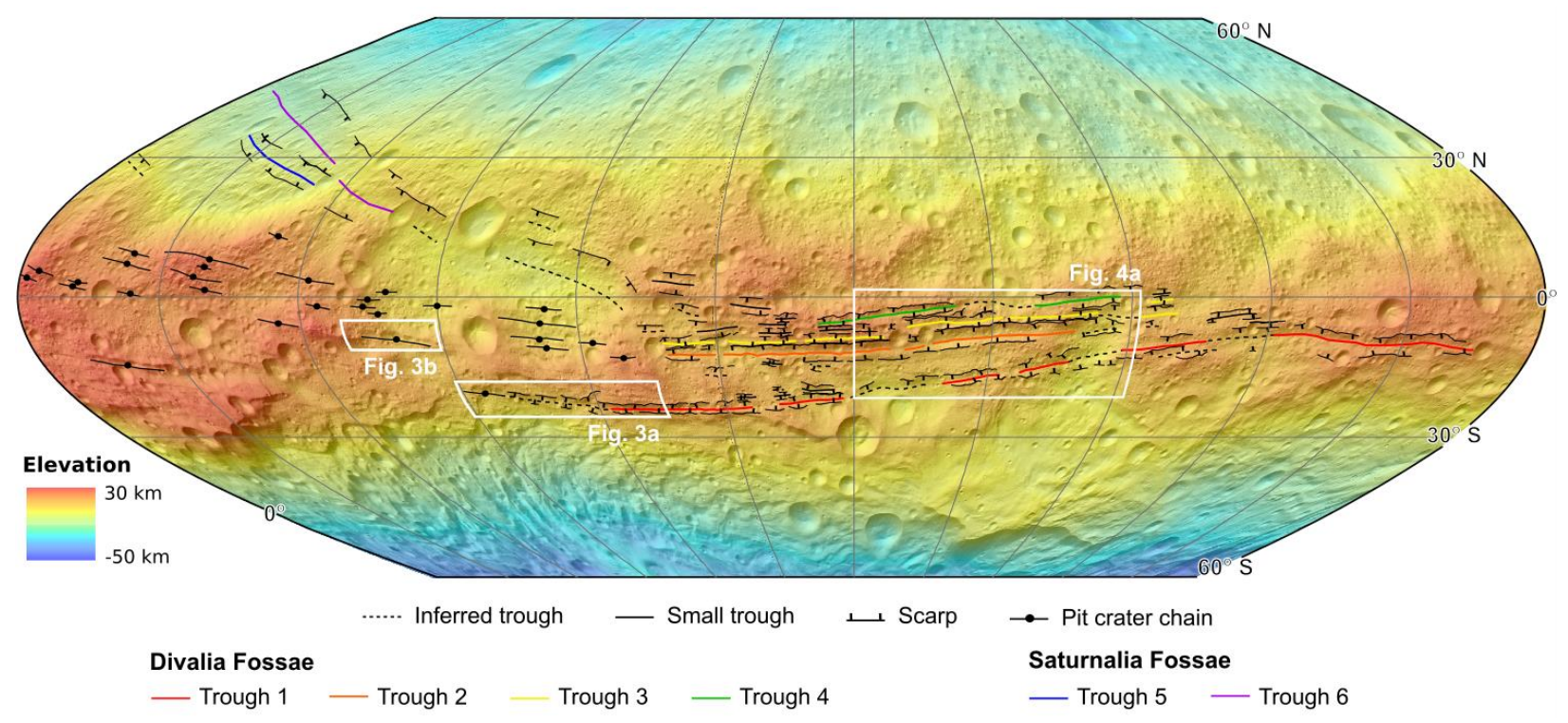

Figure 2. Digital terrain model of Vesta overlain on hillshade showing a structural map of largescale troughs and pit crater chains. The map is displayed in sinusoidal projection extending between latitudes $60^{\circ} \mathrm{N}$ to $60^{\circ} \mathrm{S}$ and longitudes $0^{\circ}$ to $30^{\circ} \mathrm{W}$. Refer to text for the definition of structural map units. Locations and geographic extents of subsequent maps are indicated by white 

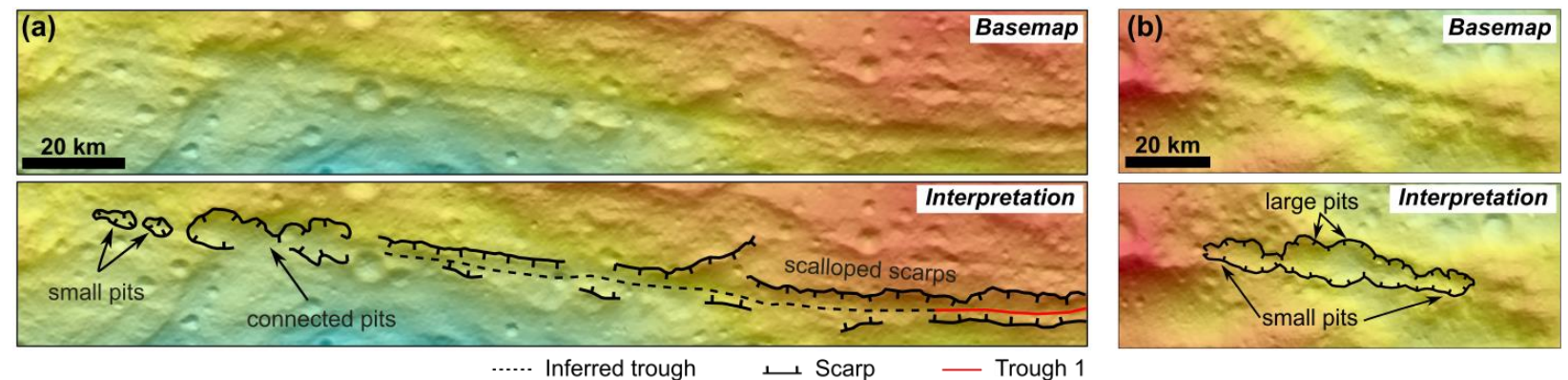

Figure 3. Base map (top) and structural interpretations (bottom) of scalloped scarps and pits and pit crater chains. (a) Trough 1 terminates into coalesced pits also showing smaller pits aligned with and beyond the termination of the trough. (b) A pit-crater chain with larger pits in the middle and smaller pits at the ends. Refer to Figure 2 for the location on Vesta. <2 column, color >

\section{Trough geomorphology}

218 having a similar slope, which led to an interpretation for the structures as grabens (Buczkowski et 219 al., 2012). Based on that interpretation, Buczkowski et al. (2012) measured the topographic 220 differences between the rim and floor of the Divalia and Saturnalia Fossae at several locations and 221 related them to the vertical displacement component of graben-bounding normal faults. Here, we 222 extract and analyze 233 topographic profiles at spacings of $5 \mathrm{~km}$ across six large troughs, to further

223 examine the cross-sectional geometries, relief, and width variations along the troughs (see 224 supplementary material). 


\subsection{Cross-sectional trough geometries}

Cross-sectional shapes for the six troughs were assessed along the 233 extracted profiles.

227 The majority of profiles contain more than one trough, such that 392 individual trough geometries

228 were analyzed. All profiles were examined for topographic changes between the trough rims to

229 identify whether the cross-sectional trough geometry is flat-floored, i.e., no major topographic

230 changes in the center of the trough, or whether a different geometry is observed. Trough geometries

231 lacking distinctive rims or superposed by impact craters are classified as inconclusive. One

232 representative profile of the Divalia Fossae is shown in Figure 4a, which shows four troughs with

233 troughs 1, 2, and 3 displaying a clear bowl shape, and trough 4 having a V-shape. Among all

234 assessed topographic profiles, 207 of our 260 conclusive troughs are not flat-floored; instead, 176

235 are bowl-shaped, and 31 of them are V-shaped. These findings show that the vast majority of

236 troughs do not show the cross-sectional geomorphology that is typical for graben. Rima Ariadaeus

237 on the Moon (Figure 4b) and grabens and horsts on the northeast flank of Alba Patera on Mars

238 (Figure 4c) are examples of typical landforms cause by normal faulting, displaying flat-floored

239 cross-sectional geometries of single of nested graben arrays, respectively. 
(a) Divalia Fossae on Vesta
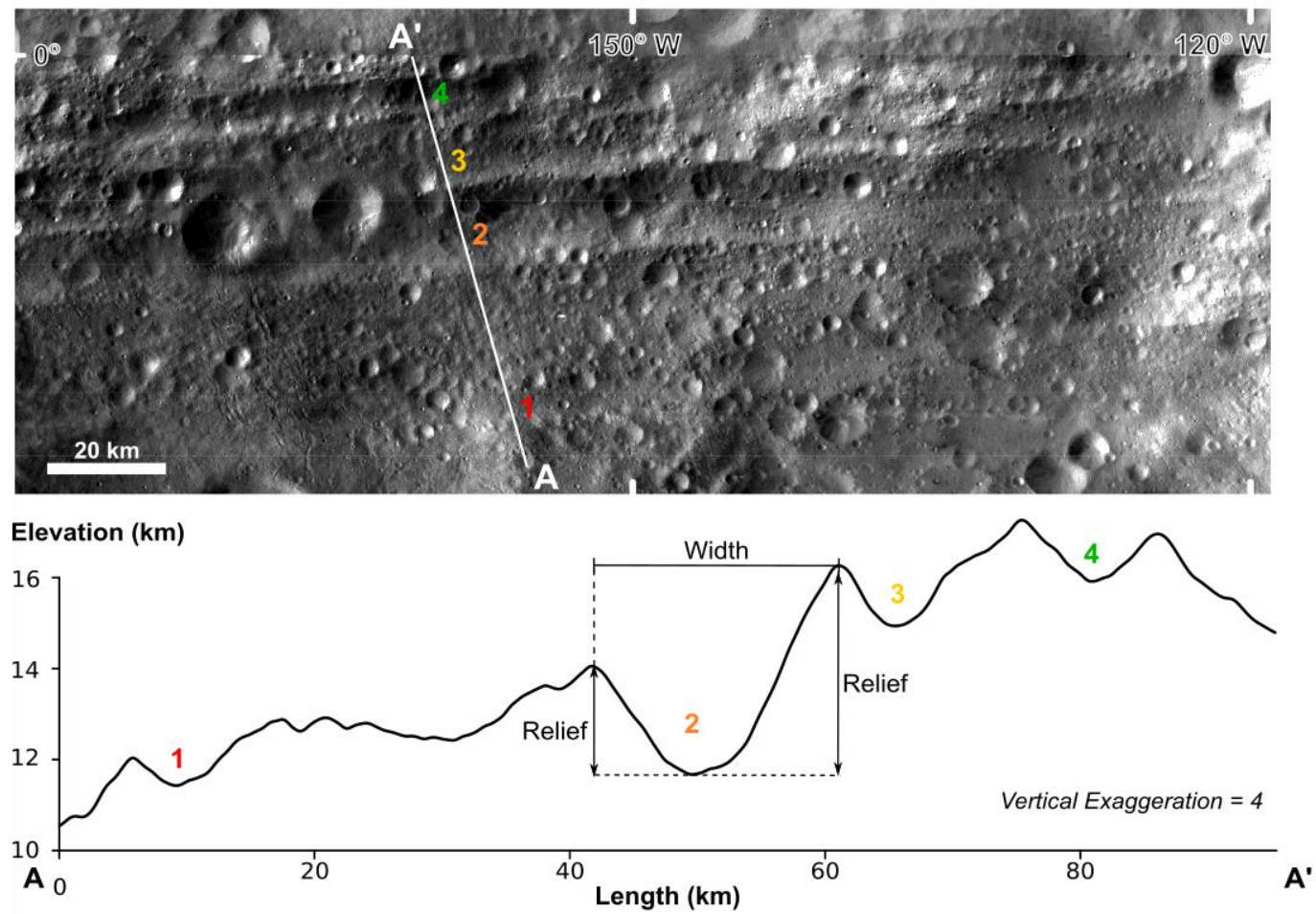

(b) Rima Ariadaeus on Moon

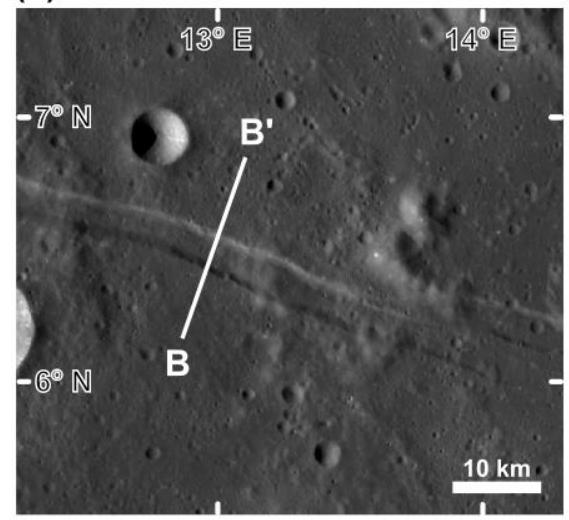

Elevation (km)

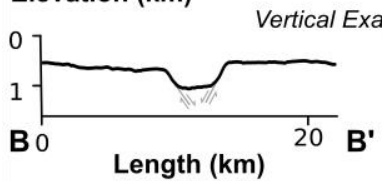

(c) Northeast flank of Alba Patera on Mars
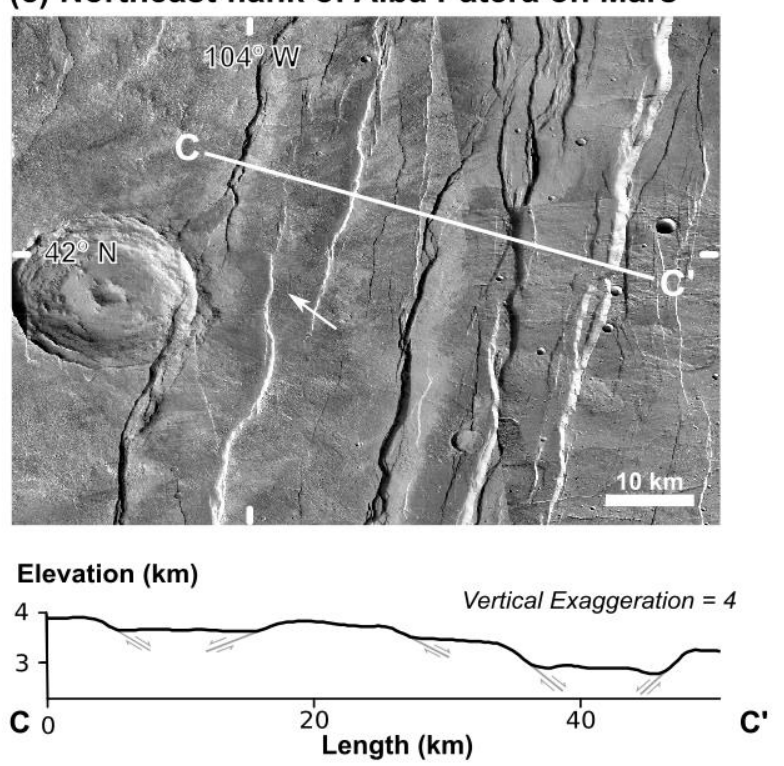

241 Figure 4. Typical topographic expressions of troughs on Vesta compared with grabens on Moon 242 and Mars. (a) Dawn FC images and topographic profile A-A' of the Divalia Fossae. Refer to

243 Figure 2 for the location on Vesta. The profile shows the geometries of four major troughs part of 
244 Divalia Fossae. The trough width and relief of two rims are labeled for trough 2. (b) Lunar 245 Reconnaissance Orbiter Camera image (Robinson et al., 2010) with a resolution of $73.24 \mathrm{~m} / \mathrm{pixel}$ 246 and topographic profile B-B' of Rima Ariadaeus on the Moon. The elevation data is based on 247 High-resolution Lunar Topography (SLDEM2015; Barker et al., 2016) with a vertical resolution 248 of $\sim 10 \mathrm{~cm}$ and horizontal resolution of $\sim 60 \mathrm{~m} / \mathrm{pixel}$. An en-echelon stepover is observed at the 249 eastern end of the graben. (c) Mars Reconnaissance Orbiter Context Camera (CTX; Malin et al., 250 2007) image with a resolution of $\sim 5 \mathrm{~m} /$ pixel and topographic profile $C$ - $C$ ' of northeast flank of 251 Alba Patera on Mars. The elevation data is based on the High Resolution Stereo Camera of Mars 252 Express (image h0068_0009; Gwinner et al., 2009) with a grid spacing of 125 m, and a vertical 253 accuracy of $\sim 20 \mathrm{~m}$. Normal fault structures are observed, including fault segments forming a relay 254 ramp on the western graben (white arrow) and multiple faulted borders at the western rim of the 255 eastern graben. The horizontal scale, vertical scale, and vertical exaggeration are the same for 256 the three topographic profiles. $<1.5$ column, color $>$

\subsection{Shape variations along troughs}

\subsubsection{Trough reliefs}

Buczkowski et al. (2012) analyzed the topographic differences between the trough floor and rim of Divalia and Saturnalia Fossae and related them to the vertical displacements of faults

262 forming grabens. We expand upon this analysis by assessing six troughs also including Divalia 263 and Saturnalia Fossae but with a denser sampling of the topographic data (supplementary material). 264 Structural reliefs for the trough-bounding scarps for each major trough are assessed at $5 \mathrm{~km}$ 265 intervals. The shortest trough, trough 5, is $115 \mathrm{~km}$ long and includes 24 measurements, whereas 
the longest trough, trough 1, with a length of $835 \mathrm{~km}$, has 168 measurements per trough-bounding scarp. The reliefs of scarps are determined by the maximum elevation differences between the trough floor and rims (Figure 4). The measured values are plotted along the normalized length of map trace for comparison of maximum reliefs of the two trough-bounding scarps to one another and with respect to the center of the trough length (Figure 5). A graben origin predicts the vertical displacements of the bounding faults, represented here by scarp reliefs, to have their maxima located centrally along the length of the trough and tapered to zero toward the tips. The shapes of the two profiles per trough, one for each of the trough-bounding scarps, are expected to mimic each other, considering that no fault segmentation and linkages are observed. As the southern portion of the Saturnalia Fossae is no longer preserved, their true maxima and location along the trough cannot be determined; nonetheless, we analyze them to investigate if part of the relief distribution profile shows characteristics typical for faults.

The two relief distributions for each of the six troughs are displayed in Figure 5. Trough 1 is separated into three segments by long muted troughs far from each other, which makes it difficult to determine if they belong to a single structure or multiple structures; the maximum reliefs are marked for each of its segments. In total, the length of trough 1 is $835 \mathrm{~km}$, and its maximum reliefs of the northern and southern rims are $4.74 \mathrm{~km}$ and $2.78 \mathrm{~km}$, respectively. Trough 2, Divalia Fossa, is $400 \mathrm{~km}$ long with maximum reliefs of $5.73 \mathrm{~km}$ on the northern rim and $2.96 \mathrm{~km}$ on the southern rim. Its northern rim has a large relief among the Divalia Fossae, consistent with the finding by Buczkowski et al. (2012). Trough 3 is $495 \mathrm{~km}$ long with maximum reliefs of $2.92 \mathrm{~km}$ and $2.82 \mathrm{~km}$ on the northern and southern rims, respectively. Trough 4 is $345 \mathrm{~km}$ long with maximum reliefs of $3.22 \mathrm{~km}$ and $2.68 \mathrm{~km}$ on the northern and southern rims, respectively. Among the 8 distributions of the Divalia Fossae, only the northern rim of trough 2 and southern rim of trough 3 display a 
289 peaked relief distribution with a maximum relief near the center along the length of the trough and 290 tapering toward the tips (Figure 5a), whereas the other 6 profiles show maximum reliefs located 291 off-center or displaying multiple peaks. Our results for Divalia Fossa are also consistent with the 292 relief distribution presented in Buczkowski et al. (2012). In addition, none of the four troughs in 293 Divalia Fossae show symmetrical shapes and the relief distributions of the two trough-bounding 294 scarps are dissimilar (Figure 5a).

For the Saturnalia Fossae, the traceable length of trough 5 is $115 \mathrm{~km}$ with the maxima of $2961.29 \mathrm{~km}$ and $3.99 \mathrm{~km}$ on the two scarps, whereas the traceable length of trough 6 is $275 \mathrm{~km}$ and its 297 maxima of structural relief are $4.20 \mathrm{~km}$ and $6.89 \mathrm{~km}$. Similar to those on the Divalia Fossae, the 298 maxima relief of the two trough-bounding scarps are not found at the same location along the 299 distribution profiles if Saturnalia Fossae (Figure 5b).

In summary, only one of 12 relief distributions shows a maximum in its center. In addition, 301 none of the troughs have relief distributions where both trough-bounding scarps have similar 302 shapes, making the troughs highly asymmetric in cross section. These findings are atypical for 303 normal faulting and thus are not consistent with the interpretation of these landforms as grabens. 
(a) Divalia Fossae
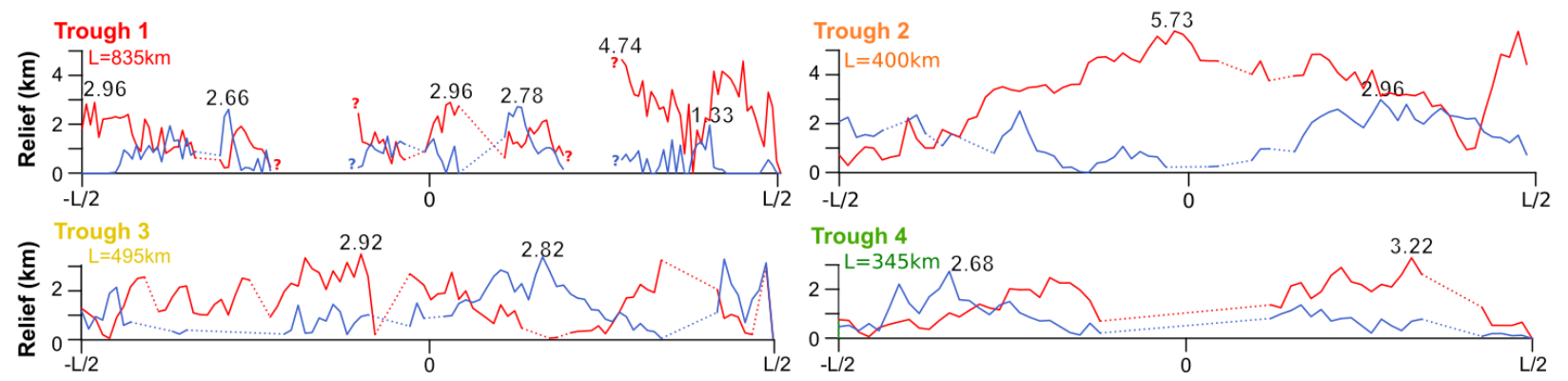

(b) Saturnalia Fossae
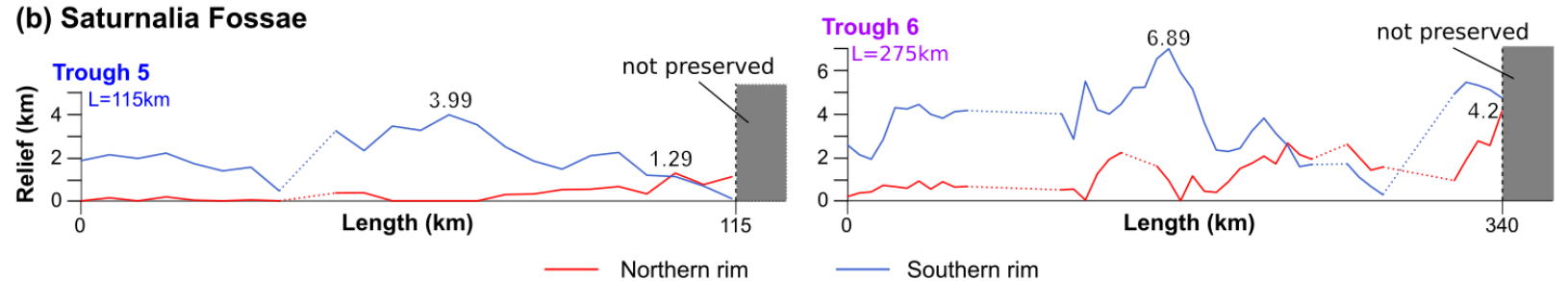

Figure 5. Relief distributions of all analyzed troughs. The reliefs of (a) Divalia Fossae are plotted along the location of the trough normalized over total trough length, L. The numerical values of maxima (in $\mathrm{km}$ ) are labeled at their locations long the trace. Scarps bounding troughs on the north are plotted in red, and southern scarps are plotted in blue. Note that the southern extent of the

Saturnalia Fossae (b) is truncated by the Divalia Fossae, and thus their total length and maximum relief are unknown. Their reliefs are plotted against the traceable length in $\mathrm{km} .<2$ columns,

311 color >

\subsubsection{Trough widths}

As with faults, opening-mode fractures typically have displacement distribution profiles with centrally located maxima that taper to zero at the fracture tips. As the mode of displacement differs, the aperture is formed perpendicular to the fracture surface and related to the trough widths. Trough widths are defined by the horizontal distance between the elevated portions of the two trough-bounding scarps measured perpendicular across the trough (Figure 4). We extract width 
measurements from the previously extracted topographic sections (supplementary material) across each of the previously analyzed troughs and plot them along the length of the trough set from west to east (Figure 6). The distributions are analyzed for the location of maxima. These individual profiles are summed to identify the cumulative widths for each of the two trough sets to explore their potential total opening-mode displacement.

The width profiles for each of the four troughs within the Divalia Fossae are displayed in Figure 6a, and the cumulative width profile is shown in Figure 6b. As with our relief analysis, trough 1 (Figure 6a) has three segments, and it is difficult to determine if it is a single structure or multiple structures. We have marked the maximum reliefs for each of its segments. The profile indicates that trough 1 generally widens toward the east with the widest measurement of $20.4 \mathrm{~km}$ occurring near the eastern tip. Troughs 2, 3, and 4 have maximum widths of $20.5 \mathrm{~km}, 15.8 \mathrm{~km}$, and $17.3 \mathrm{~km}$, respectively. The width maxima of troughs 2 to 4 occur at a similar longitudinal position on Vesta, centrally located along the length extent of the trough set (Figure 6a). These maxima are all skewed toward the east. The distribution of cumulative width summed across the strike of the Divalia Fossae shows a $\sim 800 \mathrm{~km}$ long profile with one general maximum of $60.8 \mathrm{~km}$ at the center of the overall length trace, tapering toward the tips (Figure 6b).

For the Saturnalia Fossae, the preserved portions show that troughs 5 and 6 have a maximum width of 18.9 and $42.0 \mathrm{~km}$, respectively (Figure 6c). As an unknown portion of the southern extent of this trough set is not preserved, the full extent of their width distribution cannot be determined. Hence, the relative location of their maxima along their full length and profile skewness is undetermined. The cumulative width distribution of the Saturnalia Fossae shows a $\sim 280 \mathrm{~km}$ long profile with one maximum of $56.2 \mathrm{~km}$ near $110 \mathrm{~km}$, tapering towards the western end while the eastern end is not preserved (Figure 6d). The systematic changes and shapes of the 
342 individual and cumulative profiles for both trough sets are consistent with the mechanics of opening-mode fractures, and we thus consider them as support of an opening-mode fracture origin.

\section{Divalia Fossae}

(a)

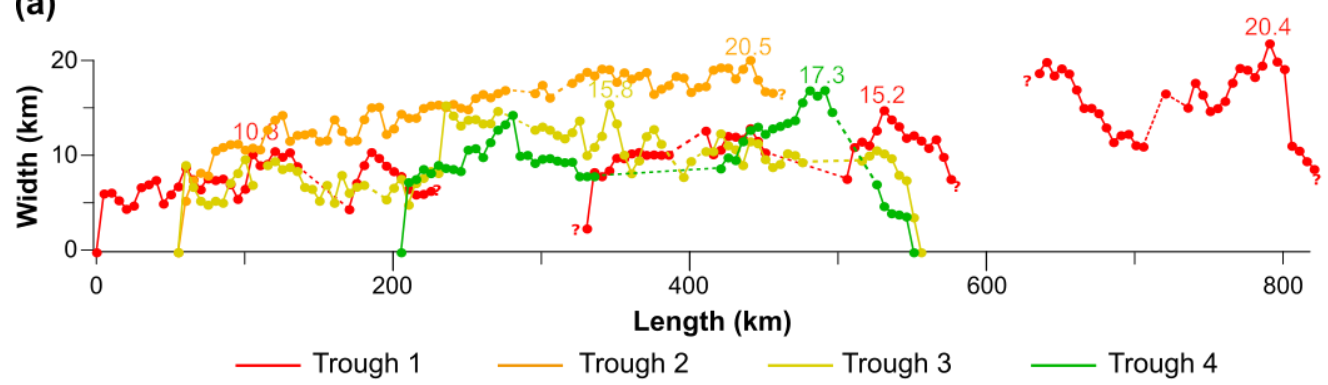

(b)

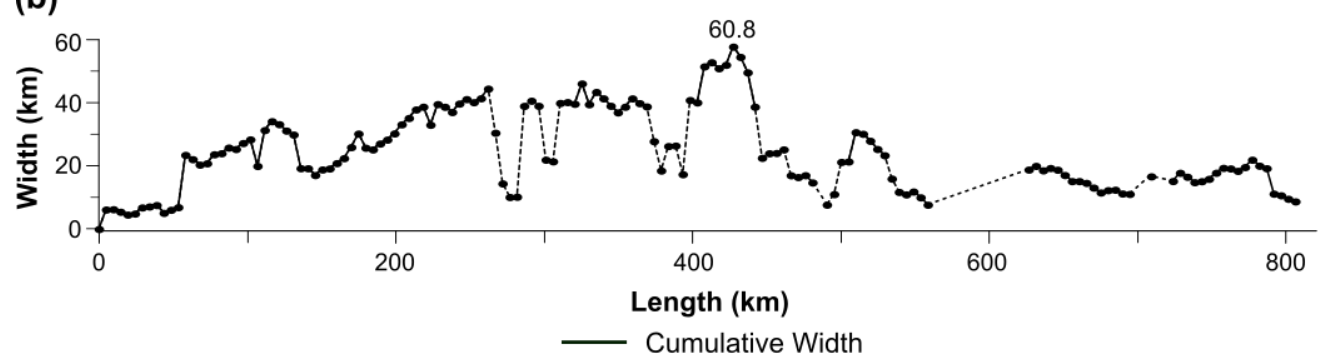

\section{Saturnalia Fossae}

(c)
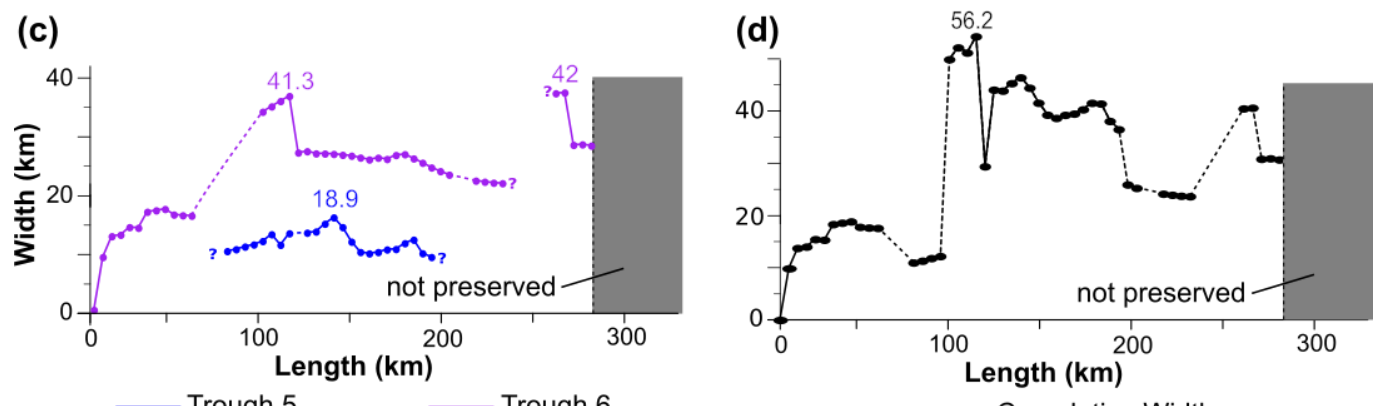

Figure 6. Width distributions of all analyzed troughs. (a) Individual and (b) cumulative width profiles of the Divalia Fossae of troughs 1 to 4. (c) Individual and (d) cumulative width profiles of

347 the Saturnalia Fossae of trough 5 and 6. The numeric values of width maxima are labeled (in $\mathrm{km}$ ) at their locations long the trace. Note that the true extent of the Saturnalia Fossae (b) is not preserved and thus the true length and maximum width are unknown. <1.5 column, color > 


\section{Lithospheric strength and fracturing behavior}

Strength-depth profiles are used to characterize the rheologic structure of Vesta's

353 lithosphere and determine the predicted fracturing behavior in its brittle regime. On a low-gravity

354 body, such as Vesta, the thickness of the total lithosphere, the gravitational acceleration-dependent

355 lithostatic pressure-depth function, and the transition from brittle to ductile behavior are all

356 important factors that need to be accounted for when assessing large fractures. Thus, the first step

357 is to derive the gravitational acceleration profile for Vesta based on previously published interior

358 models. Vesta is a differentiated asteroid, and previous studies assessed the thicknesses,

359 compositions, and densities of core, mantle, and crust using geophysical and spectral data from

360 the Dawn mission and howardite-eucrite-diogenite (HED) meteorites, for which Vesta is widely

361 believed to be the parent body. Vesta has an iron core with a radius of $\sim 108 \mathrm{~km}$ and density of

$362 \sim 7850 \mathrm{~kg} \mathrm{~m}^{-3}$ (Ermakov et al., 2014; Russell et al., 2012; Ruzicka et al., 1997), a 118 km thick

363 (Ermakov et al., 2014) olivine-rich mantle with a density of $\sim 3400 \mathrm{~kg} \mathrm{~m}^{-3}$ (Russell et al., 2012;

364 Ruzicka et al., 1997; Zuber et al., 2011), and a 36 km thick basaltic crust with a density of 2900

$365 \mathrm{~kg} \mathrm{~m}^{-3}$ (Russell et al., 2012; Ruzicka et al., 1997; Zuber et al., 2011). Using this three-layer interior

366 structure model (Figure 6a), we calculate the gravity acceleration profile of Vesta using:

$$
\frac{\delta g}{\delta r}=4 \pi G \rho_{r} r-2 \frac{g}{r}
$$

368 where $g$ is gravitational acceleration, $r$ is the radius of the body, $G$ is the gravitational constant, 369 and $\rho_{r}$ is local material density. Our calculated surface gravitational acceleration is $0.26 \mathrm{~m} / \mathrm{s}^{2}$ 370 (Figure 7b) and is consistent with the values measured by the Dawn spacecraft, which range from 3710.23 to $0.27 \mathrm{~m} / \mathrm{s}^{2}$ (Ermakov et al., 2014). The acceleration due to gravity gradually decreases with 372 depth to the lower mantle at $\sim 120 \mathrm{~km}$, where it increases until it reaches the core-mantle boundary. 
373 The gravity acceleration then drops linearly to zero at the center of the core (Figure 7b). The result 374 is consistent with the calculation by Stickle et al. (2015).

Next, we utilize our calculated gravitational acceleration profile to assess how overburden pressure, $P$, changes with depth, $z$, as given by:

$$
P(z)=-\rho_{z} z g
$$

378 The resulting pressure profile is shown in Figure 7c. Overburden pressures increases with depth in 379 a roughly linear fashion from $0 \mathrm{MPa}$ at the surface to $\sim 120 \mathrm{MPa}$ at the core-mantle boundary and 380 then increases more rapidly in the core.

(a)

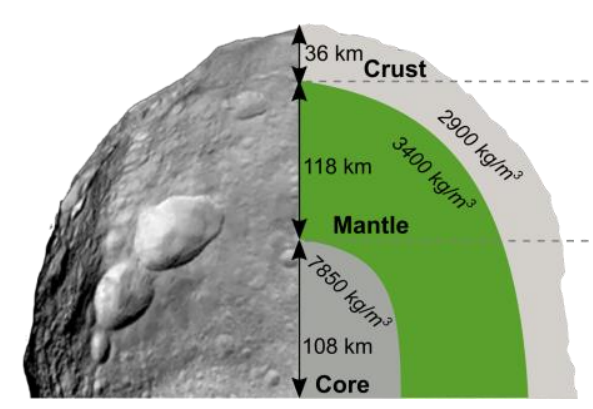

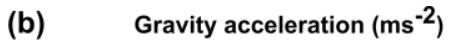

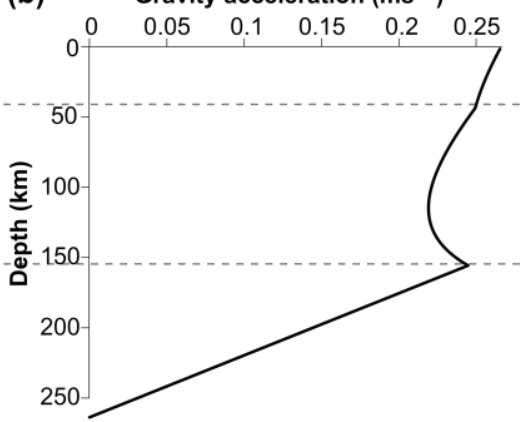

(c) Pressure (MPa)

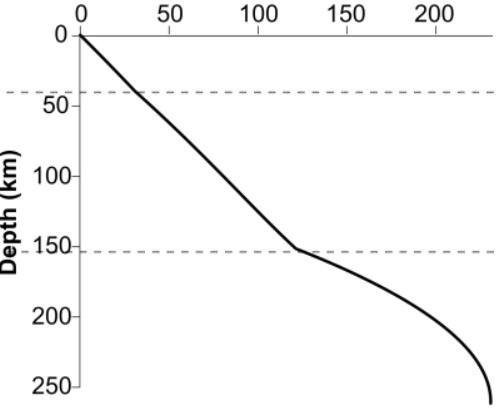

Figure 7. (a) A three layer-model of Vesta's interior was used to compute gravitational acceleration-, and pressure-depth profiles. (b) Gravitational acceleration-depth profile. (c) Pressure-depth profile. Dashed lines across the three diagrams indicate crust-mantle and mantlecore boundaries. <2 columns, color >

The overburden pressure plays an important role in defining lithospheric strength. Lithospheres are controlled by brittle and ductile properties of their constitutive rock, and their strength is determined by the weakest rheology at a certain depth for a given stress. The upper 
390 portion of a solid surface body with low temperature and confining pressure is controlled by brittle 391 behavior (Byerlee, 1978) with the strength increasing linearly with depth, independent of the rock 392 type and surface condition (Byerlee, 1978). We follow the geologic sign convention in our 393 calculations, where tensile stresses are negative and compressive stresses are positive. The rock 394 strength can be determined by the equations:

$$
\frac{\sigma_{1}}{\sigma_{3}}=\frac{s_{v}}{s_{h}}=\left(\sqrt{\mu^{2}+1}+\mu\right)^{2} \text { for extension }
$$

and

$$
\frac{\sigma_{1}}{\sigma_{3}}=\frac{S_{H}}{S_{v}}=\left(\sqrt{\mu^{2}+1}+\mu\right)^{2} \text { for shortening, }
$$

assuming that $P$ in Equation (2) corresponds to either the maximum $\left(\sigma_{1}\right)$ or minimum $\left(\sigma_{3}\right)$ principal stress component with zero pore fluid pressure, where $S_{v}$ is the vertical stress, $S_{h}$ and $S_{H}$ 400 are the minimum and maximum horizontal stresses, respectively. The coefficient of friction, $\mu$, is 401 a measure of the amount of friction existing between two sliding surfaces, and it can be determined 402 by analyses of the orientation of surfaces along which gravity sliding takes place on natural rock 403 surfaces. We consider a value of $\mu=0.6$ for crust and mantle, which is a good representation of 404 rock regardless of the rock type (Byerlee, 1978). In the lower hotter portions of the lithosphere, ductile behavior dominates by several 406 microstructural deformation mechanisms, which are combined under the term creep. Here, the 407 strength sharply decreases with increasing temperature and is defined by a thermally activated 408 power law (Burov and Diament, 1992; Mackwell et al., 1990; Ranalli and Murphy, 1987):

$$
\left(\sigma_{1}-\sigma_{3}\right)_{d}=\sqrt[n]{\frac{\dot{\varepsilon}}{A}} \exp \left(\frac{Q}{n R T}\right)
$$


410 where $\varepsilon$ is the strain rate, $A$ and $n$ are material constants, $Q$ is the activation energy of creep, $R$ is

411 the gas constant $\left(8.31447 \mathrm{~J} \mathrm{~mol}^{-1} \mathrm{~K}^{-1}\right), T$ is temperature. For our calculations we consider strain 412 rates bracketed by $10^{-14}$ and $10^{-20} \mathrm{~s}^{-1}$. The faster strain rate of $10^{-14} \mathrm{~s}^{-1}$ represents active 413 deformation, such as at orogenic belts (Pfiffner and Ramsay, 1982), whereas the slower strain rate 414 of $10^{-20} \mathrm{~s}^{-1}$ is representative of deformation found on one-plate, stagnant lid bodies, such as 415 Mercury (Crane and Klimczak, 2017), which is one to two orders of magnitude slower than that 416 found at intra-plate continental tectonic settings (Gordon, 1998). For creep parameters, we take 417 the widely-used properties of Maryland diabase $\left(n=3, A=6.3 \times 10^{-2} \mathrm{MPa}^{-\mathrm{n}} \mathrm{s}^{-1}, Q=276 \mathrm{~kJ}^{\mathrm{mol}}{ }^{-1}\right)$ 418 for the crust (Caristan, 1982), and dry olivine ( $\left.n=3, A=1 \times 10^{4} \mathrm{MPa}^{-\mathrm{n}} \mathrm{s}^{-1}, Q=510 \mathrm{~kJ} \mathrm{~mol}^{-1}\right)$ for 419 the mantle (Goetze and Evans, 1979). We apply the simulated thermal evolution from Fu et al. 420 (2014), which considered three time steps for each of their two end-member models: one with no 421 megaregolith and the other with a 5-km-thick megaregolith layer.

422 We calculated the possible lithospheric structures of Vesta (Figure 8) for the end-member 423 cases of no megaregolith (top row) and with megaregolith layer (bottom row) at different times in 424 Vesta's thermal evolution (Fu et al., 2014). The ages refer to time after the cessation of convection, 425 which has been estimated to be short (<10 Ma) after asteroid accretion (Sterenborg and Crowley, 426 2013). All strength envelopes are plotted for the crust and mantle with a total thickness of $154 \mathrm{~km}$.

427 Strength in the core is not calculated as thermal structure and other necessary material properties 428 are unknown. Any brittle behavior in the core, if present, especially with present thermal 429 conditions, should mimic the shape of the curve of the overburden pressure profile (Figure 6c).

$431 \sim 100 \mathrm{~km}$ depth are entirely brittle for every combination of our parameter space, while the lower 432 mantle is in the ductile regime only early in Vesta's history and only the lower bracket of 
433 considered strain rates. For the case without megaregolith, the brittle-ductile transition (BDT)

434 occurs at a depth of $\sim 100 \mathrm{~km}$ at 20-100 Ma (Figure 8a). At $500 \mathrm{Ma}$, the BDT migrated deeper to $435 \sim 110 \mathrm{~km}$ for a lower strain rate and $\sim 135 \mathrm{~km}$ for a higher strain rate. (Figure $8 \mathrm{~b}$ ). At present, crust 436 and mantle are completely brittle for our considered strain rates (Figure 8c). For the case with 437 megaregolith, this 5-km-thick layer slows the cooling process of the asteroid by its low thermal 438 conductivity. In Vesta's early history, the strength envelopes with insulating megaregolith layer 439 (Figure 8d) are nearly indistinguishable from the one without regolith (Figure 8a), but the lower 440 mantle remains in the ductile regime for much longer, potentially until $1500 \mathrm{Ma}$ after accretion for 441 the slow strain rates, while the crust and mantle would have been entirely brittle for fast strain rates 442 at that point in time (Figure 8e). Crust and mantle are brittle for both strain rates at present (Figure $4438 f)$. 
End member 1: no megaregolith
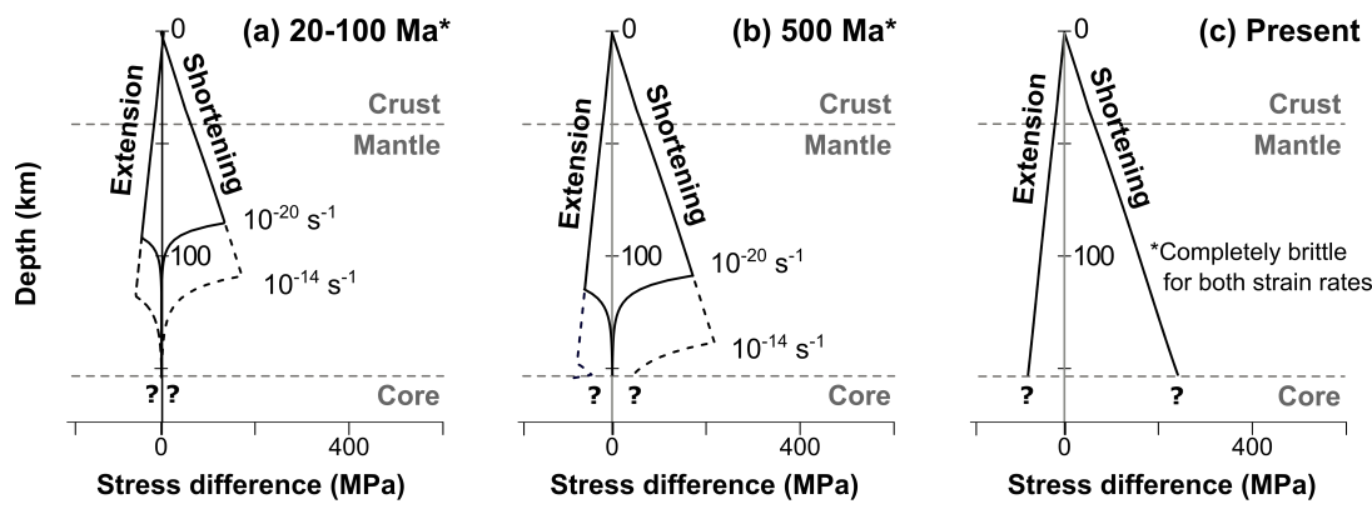

End member 2: $5 \mathrm{~km}$ thick megaregolith
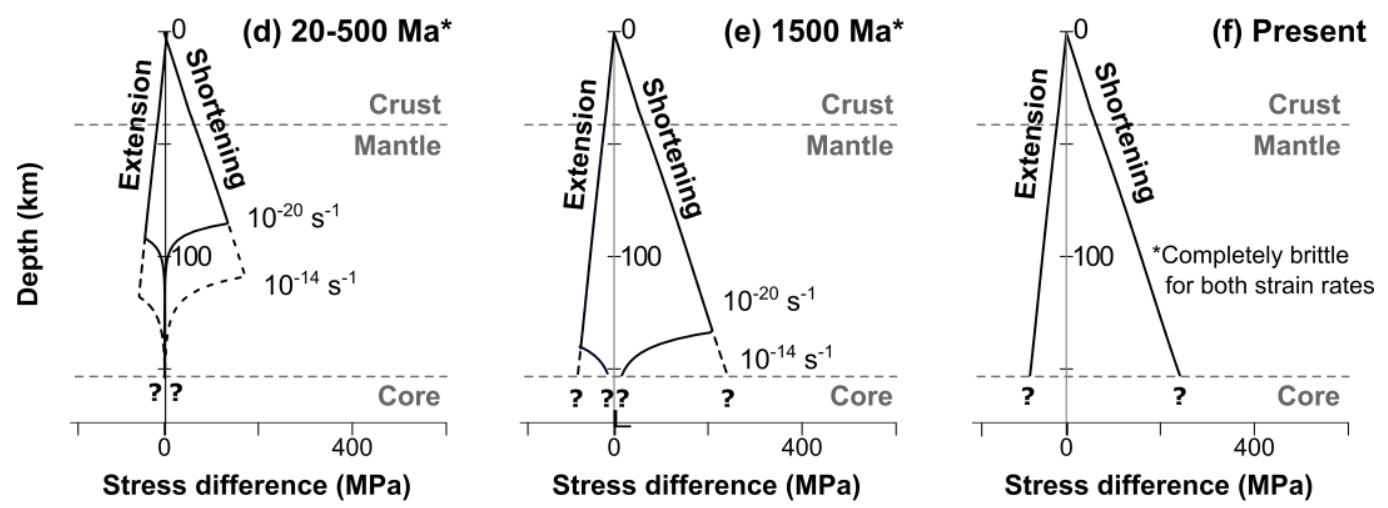

$445 \quad$ Figure 8. Strength envelopes and evolution for lithospheres under extension and shortening 446 calculated for scenarios where Vesta has no megaregolith (top row) or with $5 \mathrm{~km}$ thick 447 megaregolith (bottom row). Lithospheric structures with no megaregolith at (a) 20-100 Ma, (b) $448500 \mathrm{Ma}$, and (c) present. Lithospheric structures with insulating megaregolith at (d) 20-500 Ma, 449 (e) $1500 \mathrm{Ma}$, and (f) present. The time steps and end-members are based on the thermal evolution 450 simulated by Fu et al. (2014). The ages refer to time after the cessation of convection, which has 451 been estimated to be <10 Ma after asteroid accretion. <1.5 column, black and white> 
Our results establish that Vesta's lithosphere is thick and that the crust and much of the 454 mantle were in the brittle regime throughout Vesta's history for every combination of plausible 455 parameters. The deformation behavior in the lithosphere can thus be further assessed with a brittle 456 failure criterion. We employ the Coulomb criterion to assess the stress magnitudes needed for 457 overcoming the resistance to frictional sliding of two fracture surfaces in contact to produce faults. 458 For tectonics on Vesta, we find the Coulomb criterion most suitable, because of its simplicity, 459 relying on only a few assumptions, but allowing to include the universally applicable cohesive and 460 frictional properties of rock. The principal stress form of the Coulomb criterion, which allows 461 studying faulting, as a function of depth, is given by:

$$
\sigma_{1}=\sigma_{c}+\sigma_{3}\left(\sqrt{\mu^{2}+1}+\mu\right)^{2}
$$

463 where $\sigma_{c}$ refers to the unconfined (or uniaxial) compressive strength that replaces the cohesion 464 term of the Coulomb criterion in Mohr space. As the surface of Vesta is highly fractured by impacts, 465 we used the value for the uniaxial compressive strength of basaltic regolith of $10 \mathrm{MPa}$ (Schultz, 466 1995). Using the value of the uniaxial compressive strength of a highly fractured rock mass will 467 yield the minimum strength of Vesta's lithosphere for faults to form. Again, we consider a value 468 of $\mu=0.6$ for crust and mantle regardless of the rock type (Byerlee, 1978). For extensional 469 tectonic regimes, the overburden pressure, $P$, acts vertically as the maximum principal stress, $\sigma_{1}$. 470 We substitute our overburden pressure profile (Figure $7 \mathrm{c}$ ) for $\sigma_{1}$ in Equation (6) to calculate the 471 minimum principal stress, $\sigma_{3}$, needed for faulting in an extensional tectonic regime and plot it as 472 a function of depth (Figure 9).

The Coulomb criterion for extensional tectonic regimes of basaltic regolith on Vesta 474 predicts negative stresses above $\sim 14 \mathrm{~km}$ and positive below that (Figure 9). As per our sign 
475 convention, negative stresses are tensile, which do not produce faults but instead form joints. This 476 indicates that jointing is the preferred fracturing mechanism in the upper $\sim 14 \mathrm{~km}$ of the lithosphere,

477 with stresses favorable for frictional sliding, and thus normal faulting only below that. If Vesta's 478 lithosphere is a rock mass of better quality than regolith, then jointing as the preferred fracturing 479 mechanism would extend even deeper than $14 \mathrm{~km}$. Therefore, extensional tectonics in Vesta's 480 lithosphere are likely dominated by opening-mode fractures at least in the upper $14 \mathrm{~km}$. Only 481 fractures deeper than at least $14 \mathrm{~km}$ would be of sufficient size for the overburden to be large 482 enough to allow for frictional sliding to trigger normal faulting. Hence, even if any normal faulting 483 occurred at depth, it should have been preceded or accompanied by large opening-mode fractures 484 at the surface.

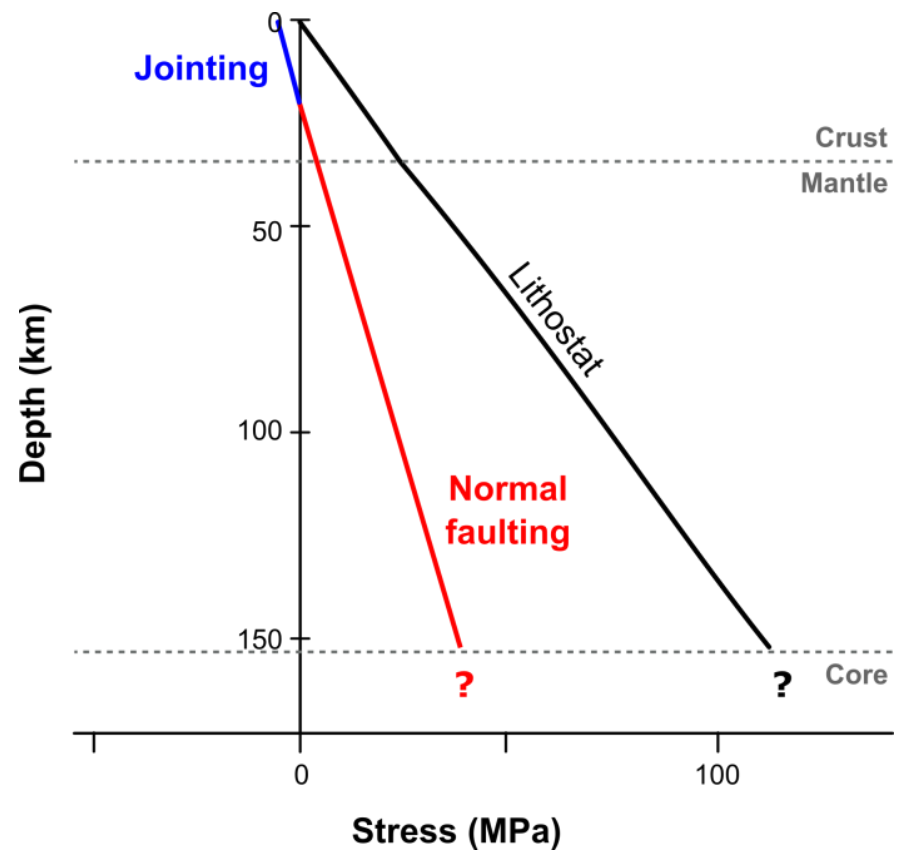

Figure 9. Solutions to the Coulomb criterion for a lithosphere under extension on Vesta, using 487 rock mass properties of a basaltic regolith $\left(\sigma_{c}=10 \mathrm{MPa}\right)$. Stresses that predict jointing are marked in blue and those predicting normal faults are indicated in red. $<1$ column, color $>$ 


\section{Discussion}

We investigated map patterns and the geomorphology of the large-scale troughs on Vesta, as well as the lithospheric fracturing behavior to assess possible fracturing behaviors that could have formed these troughs. Map patterns, geomorphology, and rock mechanical assessments individually and together have important implications for the tectonics on Vesta.

First, we observed that all large-scale troughs are isolated, continuous, and subparallel among their own sets with no diagnostic map patterns for faulting and jointing. The rims of the troughs are scalloped (Figure 3a) and that these troughs mostly resemble bowl-shaped cross498 sectional geometries (Figure 4, supplementary materials). In contrast to the finding in previous 499 studies (Buczkowski et al., 2012; Schäfer et al., 2014; Scully et al., 2014; Yingst et al., 2014), a 500 distinct flat floor is not commonly observed on the vast majority of the troughs. Some grabens 501 preserve their flat-floor geometry over billions of years on terrestrial bodies, such as on the Moon 502 (Figure 4b; Lucchitta and Watkins, 1978), Mars (Figure 4c; Kneissl et al., 2015; Ruj et al., 2019), or Mercury (Klimczak et al., 2013; Cunje and Ghent, 2016). However, considering the trough 504 geometry of a graben- or joint-origin could all be degraded into a bowl-shape by impact shaking 505 and mass wasting, our findings show only that the troughs are heavily degraded and no diagnostic 506 evidence for fault traces of graben or joint could be identified.

Although the map pattern of troughs does not distinguish faulting and jointing, pit-crater chains associated with the troughs may reveal distinctive patterns related to the origin of troughs.

509 Only one trough shows a direct transition to a pit-crater chain, which narrows toward the tips and 510 directly transitions into a pit-crater chain, which then aligns with smaller pits farther away from 
511 the end of the trough (Figure 3a). Another well-preserved pit chain was found to have larger pits

512 in the middle and smaller pits at the two ends (Figure 3b). These patterns were also observed

513 associated with grabens on Mars (Wyrick et al., 2004). There, pit crater chains have larger pits in

514 the center of the chain and smaller pits at the ends representing different stages of formation

515 (Wyrick et al., 2004). However, the Martian pits are frequently found to be located on the floor of

516 grabens (Wyrick et al., 2004), which we do not observe on Vesta. An opening-mode fracture origin

517 may be an explanation of the absence of fault-bordered pits. Additionally, the pit craters are

518 circular depressions that form by the collapse of material into subsurface voids, which may

519 represent subsurface fractures that did not propagate to the surface. In this case, the preserved pit

520 crater chain with larger pits in the center of the chain and smaller pits at the end (Figure 3b) is

521 consistent with joints, in that the maximum aperture is commonly found at the center of the length

522 with smaller apertures near the tips (e.g., Vermilye and Scholz, 1995).

The relief and width of the troughs have implications for the graben and opening-mode

524 fracture interpretation by relating them to the corresponding structural components. Trough reliefs

525 were associated with the vertical displacements of graben components by the analysis from

526 Buczkowski et al. (2012). We collected measurements of elevation differences between the trough

527 floor and rims along the trough length and observed that the relief distributions do not show a 528 general peak near the center and taper toward the tips of the troughs and that the maximum reliefs 529 are located at different locations along the bounding scarps of every structure investigated (Figure 530 5). Following observations of the mechanics of fault growth (e.g., Dawers et al., 1993; Cartwright

531 et al., 1996), our observations for the troughs would imply that the proposed graben-bounding 532 faults originated at different positions but then grew toward one another to interact and form 533 grabens. However, none of the patterns of faulting interaction, such as segmentation and linkage 
534 is observed in the mapping. Such fault growth and mismatch in locations of maximum 535 displacements are atypical for graben and therefore rule out a primarily graben origin.

Trough widths may serve as a measure for apertures of opening-mode fractures. Three out

537 of four mapped Divalia Fossae have their maximum width occurring at a similar position along 538 the trough set (Figure 6) and the cumulative width distribution shows a roughly symmetric profile 539 with one general maximum at the center of the overall length trace, tapering toward the tips. These 540 characteristics are consistent with observations of opening-mode fracture mechanics, where the 541 displacement distribution profiles display centrally located displacement maxima that taper to zero 542 at the fracture tips for individual joints (e.g., Vermilye and Scholz, 1995). The cumulative profile 543 also suggests that the troughs in the same set belong to one population, which formed under the 544 same opening event, and thus the troughs may be part of a large set of parallel joints. Such opening545 mode fracture patterns and aperture distributions are commonly observed for Earth, such as the 546 parallel joints at Arches National Park, Utah (Cruikshank and Aydin, 1994), veins in the Culpeper 547 Quarry, Virginia (Vermilye and Scholz, 1995), and the Ship Rock dikes in New Mexico (Delaney 548 and Pollard, 1981), and on Mars, such as joints in west Candor Chasma and dikes in Coprates 549 Chasma (Okubo, 2010).

The calculated lithospheric strength shows that Vesta's crust and upper mantle are 551 completely brittle for every combination of plausible parameters applicable to the asteroid. 552 Coulomb criterion predicts that in an extensional tectonic regime on Vesta, normal faulting is only 553 possible at substantial depth. The transition from opening to sliding-mode fracturing is predicted 554 by the Coulomb criterion to occur at a minimum of $14 \mathrm{~km}$ depth, but is likely deeper depending 555 on the degree of fracturing in Vesta's lithosphere. If Vesta's lithosphere possessed a moderate to 556 low degree of fracturing, jointing would be favored possibly down to the core-mantle boundary. 
557 Thus, normal faulting on Vesta is not required to explain the troughs, but even if any normal

558 faulting occurred at depth, it should have been preceded or accompanied by large opening-mode

559 fractures at the surface. Our strength calculation does not include the effect of centrifugal

560 acceleration that results from Vesta's fast rotation. The centrifugal acceleration counters the

561 overburden pressure, and hence, may even increase the depth of the jointing-faulting transition in

562 the equatorial region.

Large openings triggered by normal faulting are also observed on Earth. One prominent

564 analogue on Earth is the Almannagjá normal fault, forming the western boundary of the Pingvellir

565 Graben at the Reykjaneshryggur-Langjökull rift system of southwest Iceland. The fault is

566 accompanied by joints, or fissures, which opened up by up to $60 \mathrm{~m}$ before the fractures were large

567 and deep enough for them to be reactivated as normal faults that then produced a vertical

568 displacement of $40 \mathrm{~m}$ (Gudmundsson, 1992, 2011). The troughs on Vesta may seem to be too large

569 for joints as we know them on Earth. However, the scale of jointing is dependent on the

570 gravitational acceleration, which is much lower on Vesta and thus it is expected to have larger

571 joints than Earth or any other planet. Trough widths on Vesta are widened due to degradation and

572 the volume of slumping is unknown; thus, trough width does not represent the original aperture of

573 the joint.

574 Our geological observations are inconsistent with the graben interpretation but instead

575 point to an opening-mode fracture origin for Vesta's large-scale troughs. We propose that the

576 large-scale troughs are topographic expressions of opening-mode displacement mainly from

577 jointing and the various geometry is likely to represent degradations (Figure 10). Extension could 578 have formed joints in Vesta's surface and subsurface (Figure 10a). If the joint propagated deep 579 enough, exceeding the jointing-faulting transition, they have the potential to be reactivated as 
580 normal faults at that depth forming mixed-mode fractures. In this case, the width of the trough 581 would consist of mainly the aperture from jointing but also have a dilational component from 582 normal faulting.

583 During degradation of the troughs, the slope material on the wall of the surface opening 584 collapsed into the void, widening the initial sharp and narrow V-shaped joints and forming 585 scalloped rims (Figure 10b). Collapse above subsurface openings formed pit crater chains (Figure 586 10b). Over time, slumping and degradation due to potential slope failure and impact shaking likely 587 further widened the troughs and pit crater chains coalesced into linear troughs (Figure 10c). This 588 process produced the various observed cross-sectional geometry of flat-floored- $(n=53)$, widened 589 V-shaped- $(n=31)$, and predominantly bowl-shaped trough geometries $(n=176)$, regardless of 590 whether the joint initially formed at the surface or subsurface, as shown in Figure 10a. While 591 normal faulting could take part in the formation of these troughs, the topographic expression of 592 the trough should mostly accommodate opening-mode displacement from jointing (Figure 10a) 593 with a jointing-faulting transition at or below $14 \mathrm{~km}$ on Vesta (Figure 9). 

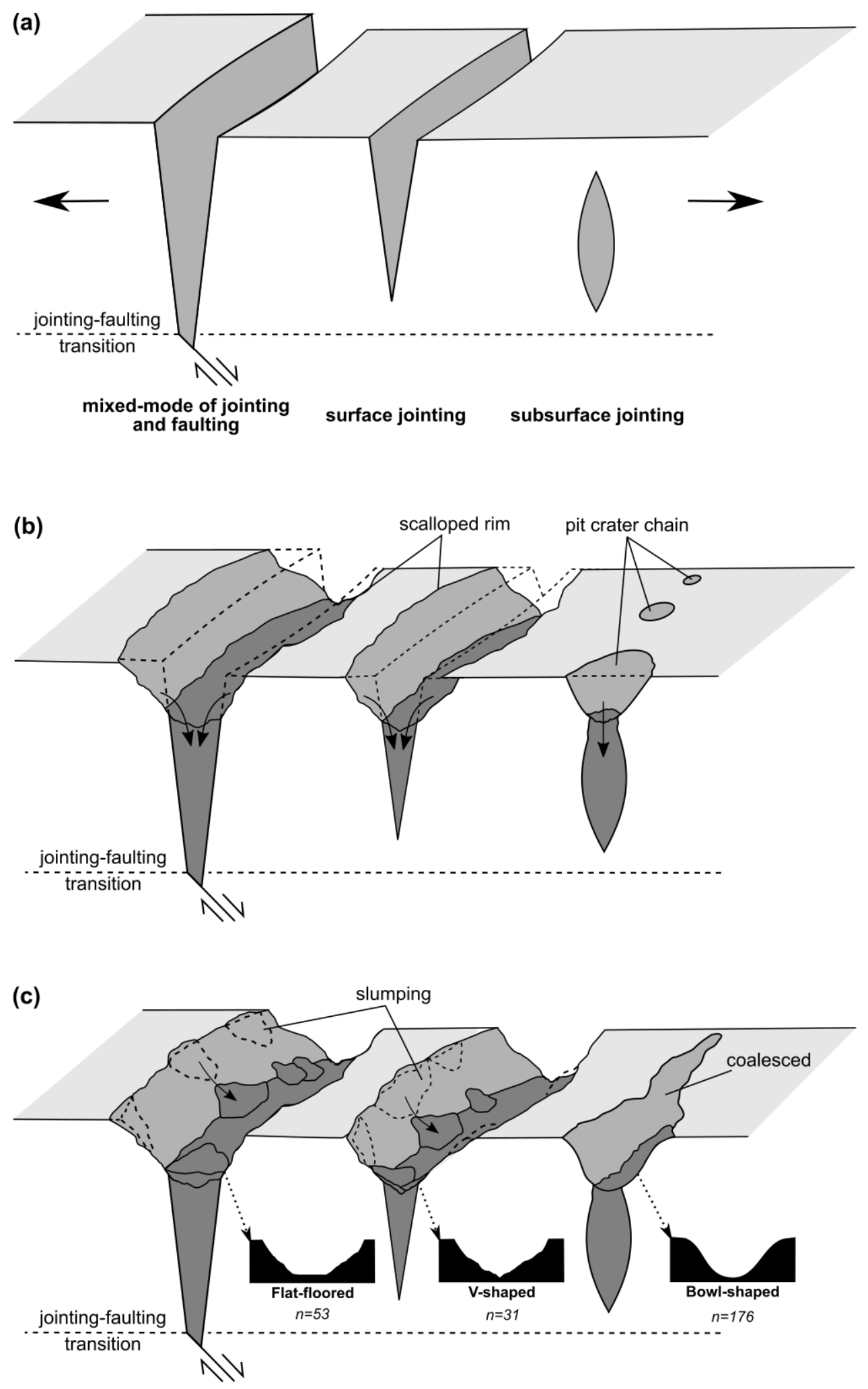
Figure 10. Diagram showing the geomorphologic evolution for opening-mode fractures on Vesta.

(a) Large-scale jointing occurs on the surface and in the subsurface. If the joint propagates deep enough, it develops into normal faulting at that depth. (b) Steep joint walls collapse into the void for the surface joints, whereas the collapse of subsurface openings forms pit crater chains. (c) Slumping and degradation further widen troughs to form and coalesce the pit crater chains to form continuous troughs. Degradation shapes the troughs into various geometries in cross section, regardless of their origin shown in (a). <1.5 column, black and white>

\section{Conclusions}

We investigated the fracture origin for the large-scale troughs on Vesta by analyzing their map patterns, cross-sectional geometries, and shape variations along the lengths of the structures. Our observations of scalloped rims that bound V- and bowl-shaped troughs, as well as the relieflength variations along the troughs, are inconsistent with grabens and are better explained by an opening-mode fracture origin. The measured individual and cumulative width-length variations and observations of pit crater chains are consistent with those of opening-mode fracture populations. We therefore conclude that the troughs on Vesta represent large joints.

This conclusion is corroborated by our calculations of Vesta's lithospheric strength and fracturing behavior. Based on the end-member thermal models from Fu et al. (2014), the solutions of strength envelopes suggest that Vesta's lithosphere displays mostly a brittle behavior throughout its geologic history. Using the Coulomb criterion for the brittle lithosphere then predicts that even for highly fractured basaltic rock masses, frictional sliding and thus normal faulting can take place only at a depth below $14 \mathrm{~km}$, and requires the formation of joints in the rock column above that 
617 depth. While normal faulting could take part in the formation of these troughs at depth, the 618 topographic expression of the trough should mostly accommodate opening-mode displacement 619 from jointing. We, therefore, further conclude that the observed relief of the trough was not 620 primarily produced by faulting and should not be considered as vertical displacement.

621 In sum, we find multiple lines of geological evidence, including map patterns, trough 622 geomorphologies, and considerations of fracture- and rock mechanics, that are, in most cases, 623 inconsistent with the previously assumed fault origin of the troughs. Instead, observations

624 overwhelmingly point to an opening-mode fracture origin of the troughs. Our findings and 625 proposed evolution of large-scale joints are important for an understanding of the tectonic history 626 of Vesta and may even help provide insight into the identification of the type and formation of 627 sizeable fractures on other small, low-gravity planetary bodies.

\section{Acknowledgments}

We thank Michael Sori, Bill McKinnon, and an anonymous reviewer, who provided 630 valuable feedback on an earlier version of this manuscript. The supplementary data of this 631 manuscript can be access at osf.io/gh5r9.

\section{References}

634 Acocella, V., Korme, T., \& Salvini, F. (2003). Formation of normal faults along the axial zone of 635 the Ethiopian Rift. Journal of Structural Geology, 25(4), 503-513. 
Barker, M. K., Mazarico, E., Neumann, G. A., Zuber, M. T., Haruyama, J., \& Smith, D. E. (2016). A new lunar digital elevation model from the Lunar Orbiter Laser Altimeter and SELENE Terrain Camera. Icarus, 273, 346-355.

Bowling, T. J., Johnson, B. C., Melosh, H. J., Ivanov, B. A., O'Brien, D. P., Gaskell, R., \& Marchi., S. (2013). Antipodal terrains created by the Rheasilvia basin forming impact on asteroid 4 Vesta. Journal of Geophysical Research: Planets, 118(9), 1821-1834.

Buczkowski, D. L., Wyrick, D. Y., Iyer, K. A., Kahn, E. G., Scully, J. E. C., Nathues, A., Gaskell, R. W., Roatsch, T., Preusker, F., Schenk, P. M., \& Corre, L. L. (2012). Largescale troughs on Vesta: A signature of planetary tectonics. Geophysical Research Letters, 39(18), L18205.

Burov, E. B., \& Diament, M. (1992). Flexure of the continental lithosphere with multilayered rheology. Geophysical Journal International, 109(2), 449-468.

Byerlee, J. D. (1978). Friction of rocks. Pure and Applied Geophysics, 116, 615-626.

Caristan, Y. (1982). The transition from high temperature creep to fracture in Maryland diabase. Journal of Geophysical Research: Solid Earth, 87(B8), 6781-6790.

Cartwright, J. A., Mansfield, C., \& Trudgill, B. (1996). The growth of normal faults by segment linkage. Geological Society, London, Special Publications, 99(1), 163-177.

Crane, K. T., \& Klimczak, C. (2017). Timing and Rate of Global Contraction on Mercury. Geophysical Research Letters, 44(7), 3082-3089. 
655 Crider, J. G., \& Pollard, D. D. (1998). Fault linkage: Three-dimensional mechanical interaction 656 between echelon normal faults. Journal of Geophysical Research: Solid Earth, 103(B10),

657 24373-24391.

658

Cruikshank, K. M., \& Aydin, A. (1994). Role of fracture localization in arch formation, Arches National Park, Utah. Geological Society of America Bulletin, 106(7), 879-891.

660

661

662

663

664

665

666

667

668

669

670

671

672

673

674

Cunje, A. B., \& Ghent, R. R. (2016). Caloris basin, Mercury: History of deformation from an analysis of tectonic landforms. Icarus, 268, 131-144.

Dawers, N. H., Anders, M. H., \& Scholz, C. H. (1993). Growth of normal faults: Displacementlength scaling. Geology, 21(12), 1107-1110.

Delaney, P. T., \& Pollard, D. D. (1981). Deformation of host rocks and flow of magma during growth of minette dikes and breccia-bearing intrusions near Ship Rock, New Mexico. U.S. Government Publishing Office.

Ermakov, A. I., Zuber, M. T., Smith, D. E., Raymond, C. A., Balmino, G., Fu, R. R., \& Ivanov, B. A. (2014). Constraints on Vesta's interior structure using gravity and shape models from the Dawn mission. Icarus, 240, 146-160.

Fossen, H. (2016). Faults. In Structural Geology (pp. 151-188). Cambridge University Press.

Fu, R. R., Hager, B. H., Ermakov, A. I., \& Zuber, M. T. (2014). Efficient early global relaxation of asteroid Vesta. Icarus, 240, 133-145.

Goetze, C., \& Evans, B. (1979). Stress and temperature in the bending lithosphere as constrained by experimental rock mechanics. Geophysical Journal International, 59(3), 463-478. 
675 Gordon, R.G. (1998). The plate tectonic approximation: Plate nonrigidity, diffuse plate

676

677

678

679

680

681

682

683

684

685

686

687

688

689

690

691

692

693

694

695 boundaries, and global plate reconstructions. Annual Review of Earth and Planetary Sciences, 26(1), 615-642.

Gudmundsson, A. (1992). Formation and growth of normal faults at the divergent plate boundary in Iceland. Terra Nova, 4(4), 464-471.

Gudmundsson, A. (2011). Rock fractures in geological processes. Cambridge University Press.

Gwinner, K., Scholten, F., Spiegel, M., Schmidt, R., Giese, B., Oberst, J., Heipke, C., Jaumann, R., \& Neukum, G. (2009). Derivation and validation of high-resolution digital terrain models from Mars Express HRSC data. Photogrammetric Engineering \& Remote Sensing, 75(9), 1127-1142.

Hauber, E., \& Kronberg, P. (2005). The large Thaumasia graben on Mars: Is it a rift? Journal of Geophysical Research: Planets, 110(E7), E07003.

Holland, M., Urai, J. L., \& Martel, S. (2006). The internal structure of fault zones in basaltic sequences. Earth and Planetary Science Letters, 248(1-2), 301-315.

Jaumann, R., Williams, D. A., Buczkowski, D. L., Yingst, R. A., Preusker, F., Hiesinger, H., Schmedemann, N., Kneissl, T., Vincent, J. B., Blewett, D. T., \& Buratti, B. J. (2012). Vesta's shape and morphology. Science, 336(6082), 687-690.

Klimczak, C., Ernst, C. M., Byrne, P. K., Solomon, S. C., Watters, T. R., Murchie, S. L., Preusker, F., \& Balcerski, J. A. (2013). Insights into the subsurface structure of the Caloris basin, Mercury, from assessments of mechanical layering and changes in long-wavelength topography. Journal of Geophysical Research: Planets, 118(10), 2030-2044. 
Kneissl, T., Michael, G. G., Platz, T., \& Walter, S. H. G. (2015). Age determination of linear surface features using the Buffered Crater Counting approach-Case studies of the Sirenum and Fortuna Fossae graben systems on Mars. Icarus, 250, 384-394.

Lucchitta, B. K., \& Watkins, J. A. (1978). Age of graben systems on the Moon. In Lunar and Planetary Science Conference Proceedings (Vol. 9, pp. 3459-3472).

Mackwell, S. J., Bai, Q., \& Kohlstedt, D. L. (1990). Rheology of olivine and the strength of the lithosphere. Geophysical Research Letters, 17(1), 9-12.

Malin, M. C., Bell, J. F., Cantor, B. A., Caplinger, M. A., Calvin, W. M., Clancy, R. T., Edgett, K. S., Edwards, L., Haberle, R. M., James, P. B., \& Lee, S. W. (2007). Context camera investigation on board the Mars Reconnaissance Orbiter. Journal of Geophysical Research: Planets, 112(E5), E05S04.

Melosh, H. J., \& Williams Jr, C. A. (1989). Mechanics of graben formation in crustal rocks: A finite element analysis. Journal of Geophysical Research: Solid Earth, 94(B10), 1396113973.

Okubo, C. H. (2010). Structural geology of Amazonian-aged layered sedimentary deposits in southwest Candor Chasma, Mars. Icarus, 207(1), 210-225.

Okubo, C. H., \& Martel, S. J. (1998). Pit crater formation on Kilauea volcano, Hawaii. Journal of Volcanology and Geothermal Research, 86(1-4), 1-18.

Olson, J. E. (2003). Sublinear scaling of fracture aperture versus length: An exception or the rule? Journal of Geophysical Research, 108(B9), 2413. 
Peacock, D. C. P., \& Sanderson, D. J. (1994). Geometry and development of relay ramps in normal fault systems. AAPG bulletin, 78(2), 147-165.

Pfiffner, O. A., \& Ramsay, J. G. (1982). Constraints on geological strain rates: arguments from finite strain states of naturally deformed rocks. Journal of Geophysical Research: Solid Earth, 87(B1), 311-321.

Pollard, D. D., \& Aydin, A. (1988). Progress in understanding jointing over the past century. Geological Society of America Bulletin, 100(8), 1181-1204.

Preusker, F., Scholten, F., Matz, K. D., Roatsch, T., Jaumann, R., Raymond, C. A., \& Russell, C. T. (2014). Global shape of (4) Vesta from Dawn FC Stereo images. Vesta in the light of Dawn: First exploration of a protoplanet in the asteroid belt, 1773, 2027.

Ranalli, G., \& Murphy, D. C. (1987). Rheological stratification of the lithosphere. Tectonophysics, 132(4), 281-295.

Robinson, M. S., Brylow, S. M., Tschimmel, M., Humm, D., Lawrence, S. J., Thomas, P. C., Denevi, B. W., Bowman-Cisneros, E., Zerr, J., Ravine, M. A., \& Caplinger, M. A. (2010). Lunar reconnaissance orbiter camera (LROC) instrument overview. Space science reviews, $150(1-4), 81-124$.

Ruesch, O., Hiesinger, H., Blewett, D. T., Williams, D. A., Buczkowski, D., Scully, J., Yingst, R. A., Roatsch, T., Preusker, F., Jaumann, R., \& Russell, C. T. (2014). Geologic map of the northern hemisphere of Vesta based on Dawn Framing Camera (FC) images. Icarus, 244, $41-59$. 
Ruj, T., Komatsu, G., Pasckert, J. H., \& Dohm, J. M. (2019). Timings of early crustal activity in southern highlands of Mars: Periods of crustal stretching and shortening. Geoscience Frontiers, 10(3), 1029-1037.

Russell, C. T., \& Raymond, C. A. (2011). The dawn mission to Vesta and Ceres. The Dawn Mission to Minor Planets 4 Vesta and 1 Ceres, 3-23.

Russell, C. T., Raymond, C. A., Coradini, A., McSween, H. Y., Zuber, M. T., Nathues, A., Sanctis, M. C. D., Jaumann, R., Konopliv, A. S., Preusker, F., \& Asmar, S. W. (2012). Dawn at Vesta: Testing the protoplanetary paradigm. Science, 336(6082), 684-686.

Ruzicka, A., Snyder, G. A., \& Taylor, L. A. (1997). Vesta as the howardite, eucrite and diogenite parent body: Implications for the size of a core and for large-scale differentiation. Meteoritics \& Planetary Science, 32(6), 825-840.

Schäfer, M., Nathues, A., Williams, D. A., Mittlefehldt, D. W., Corre, L. L., Buczkowski, D. L., Kneissl, T., Thangjam, G. S., Hoffmann, M., Schmedemann, N., \& Schäfer, T. (2014). Imprint of the Rheasilvia impact on Vesta-Geologic mapping of quadrangles Gegania and Lucaria. Icarus, 244, 60-73.

Schultz, R. A. (1995). Limits on strength and deformation properties of jointed basaltic rock masses. Rock Mechanics and Rock Engineering, 28(1), 1-15.

Schultz, R. A. (1997). Displacement-length scaling for terrestrial and Martian faults: Implications for Valles Marineris and shallow planetary grabens. Journal of Geophysical Research: Solid Earth, 102(B6), 12009-12015. 
Schultz, R. A., Moore, J. M., Grosfils, E. B., Tanaka, K. L., \& Mege, D. (2007). The Canyonlands model for planetary grabens: Revised physical basis and implications. In M. Chapman (Ed.), The Geology of Mars: Evidence from Earth-Based Analogs (pp. 371-399). Cambridge University Press.

Schultz, R. A., Okubo, C. H., \& Wilkins, S. J. (2006). Displacement-length scaling relations for faults on the terrestrial planets. Journal of Structural Geology, 28(12), 2182-2193.

Scully, J. E., Yin, A., Russell, C. T., Buczkowski, D. L., Williams, D. A., Blewett, D. T., Buesch, O., Hiesinger, H., Corre, L. L., Mercer, C., \& Yingst, R. A. (2014). Geomorphology and structural geology of Saturnalia Fossae and adjacent structures in the northern hemisphere of Vesta. Icarus, 244. 23-40.

Sierks, H., Keller, H. U., Jaumann, R., Michalik, H., Behnke, T., Bubenhagen, F., \& BŘttner, I. (2011). The Dawn Framing Camera. Space science reviews, 163, 263-327.

Smith, D. E., Zuber, M. T., Frey, H. V., Garvin, J. B., Head, J. W., Muhleman, D. O., Pettengill, G. H., Phillips, R. J., Solomon, S. C., Zwally, H. J., \& Banerdt, W. B. (2001). Mars Orbiter Laser Altimeter: Experiment summary after the first year of global mapping of Mars. Journal of Geophysical Research: Planets, 106(E10), 23689-23722.

Sterenborg, M. G., \& Crowley, J. W. (2013). Thermal evolution of early solar system planetesimals and the possibility of sustained dynamos. Physics of the Earth and Planetary Interiors, 214, 53-73.

Stickle, A. M., Schultz, P. H., \& Crawford., D. A. (2015). Subsurface failure in spherical bodies: A formation scenario for linear troughs on Vesta's surface. Icarus, 247, 18-34. 
777 Vermilye, J. M., \& Scholz, C. H. (1995). Relation between vein length and aperture. Journal of $778 \quad$ Structural Geology, 17(3), 423-434.

779 Wyrick, D., Ferrill, D. A., Morris, A. P., Colton, S. L., \& Sims., D. W. (2004). Distribution, 780 morphology, and origins of Martian pit crater chains. Journal of Geophysical Research: $781 \quad$ Planets, 109(E6), E06005.

782 Yingst, R. A., Mest, S. C., Berman, D. C., Garry, W. B., Williams, D. A., Buczkowski, D., 783 Jaumann, R., Pieters, C. M., Sanctis, M. C. D., Frigeri, A., \& Corre, L. L. (2014). Geologic 784 mapping of Vesta. Planetary and Space Science, 103, 2-23.

785 Zuber, M. T., McSween, H. Y., Binzel, R. P., Elkins-Tanton, L. T., Konopliv, A. S., Pieters, C. 786 M., \& Smith, D. E. (2011). Origin, internal structure and evolution of 4 Vesta. Space $787 \quad$ Science Reviews, 63, 77-93. 